CORRECTION

https://doi.org/10.1038/s41586-018-0572-6

\title{
Publisher Correction: Xenon isotopic constraints on the history of volatile recycling into the mantle
}

Rita Parai \& Sujoy Mukhopadhyay

Correction to: Nature https://doi.org/10.1038/s41586-018-0388-4, published online 08 August 2018.

In this Letter, owing to a production error, the arrows in the middle panel of Fig. 1 were wrongly coloured. In the Fig. 2 legend, "a single $\left({ }^{130} X_{\mathrm{d}}^{\mathrm{k}}\right), \beta$ pair" should read "a single $\left({ }^{130} X_{\mathrm{d}}^{\mathrm{k}}, \beta\right)$ pair" and " $10-10 \mathrm{Gyr}^{-1}$ and $10^{-8} \mathrm{Gyr}^{-1}$ " should read " $10^{-10} \mathrm{yr}^{-1}$ and $10^{-8} \mathrm{yr}^{-1}$ ". In the second sentence after equation (2) and in the legend to Extended Data Fig. 3,

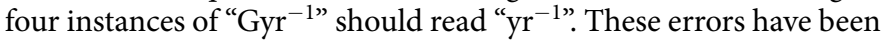
corrected online. 